\title{
Integration Host Factor: A Protein for All Reasons
}

\author{
David I. Friedman \\ Department of Microbiology and Immunology \\ University of Michigan \\ Ann Arbor, Michigan 48109-0620
}

The identification and characterization of the Escherichia coli DNA binding protein integration host factor (IHF) is an elegant example of how a well-characterized virus can be employed in the analysis of a host function. In this case, Nash and coworkers, through their landmark in vitro studies of coliphage $\lambda$ site-specific recombination (reiewed in Nash, 1981), have identified a protein that plays roles not only in other recombination reactions, but also in DNA replication and regulation of gene expression.

IHF belongs to a class of structurally related "histonelike" proteins that can wrap DNA into higher-order structures (Drlica and Rouviere-Yaniv, 1987). The most abundant of these proteins in $\mathrm{E}$. coli is $\mathrm{HU}$, and others have been found in a number of bacterial genera as well as archaebacteria.

In addition to site-specific recombination, other aspects of $\lambda$ development influenced by IHF have been fertile sources of information about this protein. I will initially focus on studies with $\lambda$ that serve to present the basic information about IHF and then examine the various roles for IHF derived from studies of $E$. coli and some of its other phages and plasmids.

\section{Phage $\lambda$}

\section{Site-Specific Recombination}

An infecting $\lambda$ can either grow lytically or form a lysogen. The latter occurs by integration of the circular phage genome into the host chromosome and shutoff of expression of most phage genes by repressor. Removal of repression leads to excision of the phage genome and production of progeny phage. These recombination events are site specific: integration requires the bacterial attB and phage attP sites, and excision requires the hybrid attL and attR sites that flank the integrated prophage (Figure 1). The product of the phage int gene is necessary for both reactions, while excision also requires the product of the phage xis gene. (For details on $\lambda$ site-specific recombination, see reviews by Weisberg and Landy, 1983; Campbell, 1983; Sadowski, 1986; Miller, 1988.)

An in vitro assay revealed that Int, a type I topoisomerase, is the site-specific recombinase that catalyzes strand exchange at the unique att sites. IHF is required for both integrative and excisive recombination; the former also requires a supercoiled attP DNA substrate. There is an asymmetry in structure of the substrates (Figure 2): attP ( $\sim 230 \mathrm{bp}$ ) is complex, containing seven binding sites for Int, one for Xis, and three for IHF ( $\mathrm{H}_{1}, \mathrm{H}_{2}$, and $\mathrm{H}^{2}$; attB (25 bp) is simple, containing only two weak binding sites for Int (Figure 2). The two att sites share a common core of $15 \mathrm{bp}$ at the site of recombination. It has been proposed
(Bushman et al., 1985) that the directionality of the reaction is regulated by the relative location of the phage arms - that is, on the same att site for integration and on different att sites for excision.

The isolation of host mutants that fail to support $\lambda$ sitespecific recombination (Miller et al., 1979) provided the means both to identify the genes encoding the two subunits of the $20,000 \mathrm{M}_{\mathrm{r}}$ IHF protein and to study the role of IHF in a variety of physiological processes. The himA gene (located at min 38) encodes the 10,500 $\mathrm{M}_{\mathrm{r}}$ IHF $\alpha$ subunit (Miller, 1984; Mechulam et al., 1985), and the hip/himD gene (located at $\min 25$ ) encodes the 9,500 $M_{r}$ IHFB subunit (Flamm and Weisberg, 1985). (For the latter gene, the combined nomenclature will be used since the gene has been called both hip and himD in the literature.) IHF is not an essential function in $E$. coli, and homologous recombination is not impaired in him or hip mutants.

Analysis of the regulation of himA and hip/himD expression is complicated by the fact that transcription of both genes appears to initiate from more than one promoter. Initiation for himA can occur from three promoters, and, depending on the promoter, himA can be part of larger operons (Miller, 1984; Mechulam et al., 1987); transcription of hip/himD initiates from two promoters, one adjacent to the gene and another $5^{\prime}$ of the upstream rpsA gene (Flamm and Weisberg, 1985). There is evidence for autogenous regulation of IHF expression. Mutations in either gene lead to increased synthesis of IHF $\alpha$ (Miller, 1981). Although putative binding sites for IHF (see below) have been identified near some of these promoters, functional roles for these sites have not been established. The expression of himA is regulated also by LexA, which represses SOS-responsive genes (Miller et al., 1981; Mechulam et al., 1987). Although studies with lexA point mutations suggest that himA, like other members of the SOS regulon, is repressed by LexA, the promoters from which himA is known to be transcribed do not contain the LexA binding sequence.

Phage $\lambda$ mutants proficient in site-specific recombination in him or hip mutant hosts have been isolated. Even though the mutants, int-h (Miller et al., 1980) and xin, were obtained by different selections, they carry the same base pair change in the int gene (Bear et al., 1987). The int-h mutation also increases the frequency at which $\lambda$ integrates at secondary att sites varying slightly from the att $B$ sequence. In vitro assays confirm that the mutant Int-h protein functions without IHF, and under these conditions does not respond to supercoiling of the attP DNA (LangeGustafson and Nash, 1984).

Lambdoid phage $\varphi 80$ fails to lysogenize him or hip mutants even though its target on the bacterial chromosome is not the attB of $\lambda$ (Miller and Friedman, 1977). Analysis of the att sites of $\varphi 80$ and another lambdoid phage, P22 (which integrates at yet another site), reveals that the three att sites differ significantly in sequence, but share common structural features (Leong et al., 1985). There is a 


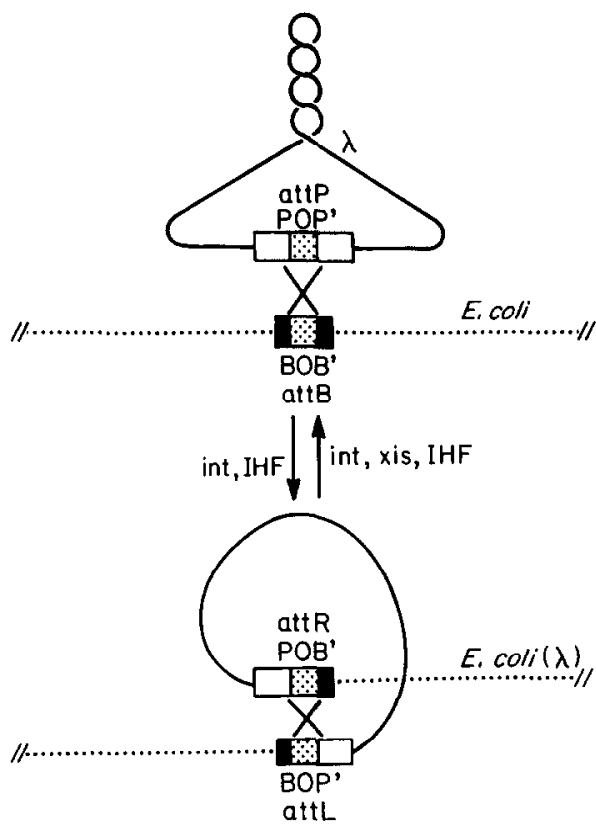

Figure 1. Integration and Excision of $\lambda$ from the $E$. coli Chromosome True to the model first proposed by Campbell (1962), $\lambda$ integrates as circular DNA. Indicated are the more complex phage attP site and the less complex bacterial attB site (see Figure 2). The integrated prophage generates different att sites, attR and attL. $P$ and $B$ represent phage- and bacterial-specific DNA, respectively, and $O$ is the core sequence common to all four att sites where the site-specific recombination (indicated by the large $x s$ ) occurs. The proteins required for recombination are indicated.

common core (a small sequence where recombination occurs) unique for each phage, and the attP sites all bind IHF. The actual number of binding sites varies.

A consensus IHF binding sequence was derived by comparing IHF-protected sites in attP as well as three nonatt sites (Craig and Nash, 1984). This information, together with later footprinting studies, yields the consensus sequence YAANNNNTTGATW (Gamas et al., 1987b; Gardner and Nash, 1986; Leong et al., 1985). Sequences that resemble the consensus but have not been demonstrated to bind IHF will be called "putative" IHF sites, while those with demonstrated binding will be called IHF sites. IHF sites are usually found in AT-rich regions; context must be important since IHF binds poorly to other sites with excellent matches to the consensus sequence (Gamas et al., 1987b; Leong et al., 1985), and sequences flanking the consensus influence binding (Prentki et al., 1987). Mutations in each of the attP IHF sites reduce IHF binding. Because reductions in binding affinities are not always matched by changes in recombination, it has been suggested that the various IHF sites are not functionally equivalent and that there may be cooperative binding of proteins at att sites (Gardner and Nash, 1986; Thompson et al., 1986).

Cooperative binding has been demonstrated for Int and IHF at attP (Richet et al., 1986) and for Int, Xis, and IHF at attR (Bushman et al., 1985). Topological studies demonstrate that the att sites and associated proteins are

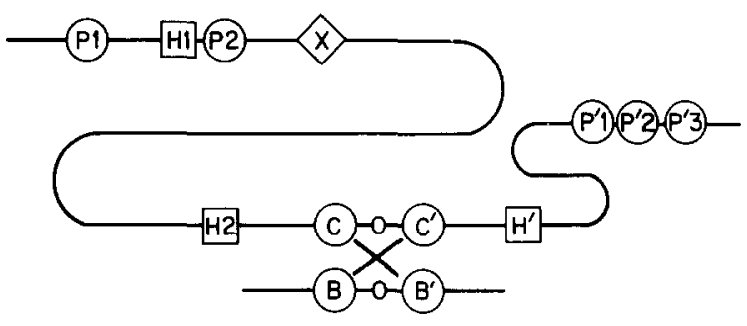

Figure 2. Distribution of Protein Binding Sites in the attP and attB Regions

Int sites are circled: $P$ and $P^{\prime}$ represent sites in the left and right arms, respectively, of the phage genome, and $\mathrm{B}, \mathrm{B}^{\prime}, \mathrm{C}$, and $\mathrm{C}^{\prime}$ represent sites in the common core. $\mathrm{H}=\mathrm{IHF}$ sites: $\mathrm{H}$ and $\mathrm{H}^{\prime}$ represent sites in the left and right arms, respectively. $X=$ an $X$ is site. The large $X$ indicates the region of crossover. See Weisberg and Landy (1983) for a more detailed discussion.

wrapped into a tight configuration forming a higher-order structure resembling a nucleosome (Pollock and Nash, 1983); its ultimate form reflects a complex set of protein-protein and protein-DNA interactions (Thompson et al., 1987). The term "intasome" (Better et al., 1983) has been appropriated to describe this structure. Formation of the attP intasome requires both Int and IHF and is facilitated by a supercoiled DNA substrate; its stability and activity in recombination depend on the magnitude and sign of the supercoiling. Richet et al. (1988) have shown that for integrative recombination, only the attP DNA appears to bind proteins. Since binding of Int to aftB is extremely weak, they have concluded that attB DNA enters the reaction naked. Moreover, using differing core sequences, it was shown that homologous pairing between the strands of the recombining DNAs does not appear necessary for synapsis or any of the steps prior to synapsis. Homology, it was concluded, is required postsynaptically for strand exchange, and synapsis results from protein-protein and protein-DNA interactions in the intasome.

A role for IHF in the intasome is suggested by studies demonstrating that IHF binding to any one of its sites within attP bends the DNA (Robertson and Nash, 1988). The final form of the intasome is likely to reflect the interaction of IHF, supercoiling, and one segment of attP that bends independently of any bound protein. From a deterministic point of view, the relative placement of IHF binding sites might allow IHF to bend and shape the intasome into an active configuration. Confounding this neat picture is the fact that recombination catalyzed by the mutant int-h protein is observed in the absence of IHF and without supercoiled substrate DNA (Lange-Gustafson and Nash, 1984). Perhaps Int-h is capable of forming an active structure in the absence of IHF: electron microscopic studies show that Int $^{+}$protein in the absence of IHF does form a condensed structure with attP and attL (Better et al., 1982).

The Cohesive Ends

IHF plays a role in the site-specific staggered cleavage reaction catalyzed by the $\lambda$ terminase (encoded by Nu1 
and $A$ ). This reaction produces monomer-length genomes from a concatameric substrate and creates the 12 nucleotide single-strand cohesive end, cos (reviewed by Feiss, 1986). DNAase I footprinting demonstrates that IHF binds with varying strength to five of six sites previously identified as potential IHF sites. The strongest IHF site in the cos region is composed of overlapping consensus sequences (Xin and Feiss, 1988). Since $\lambda$ grows relatively well in him or hip mutants (the burst size is slightly reduced), IHF is probably dispensable for the terminase reaction. Surprisingly, there is a strong dependence for IHF in the in vitro $\lambda$ packaging reaction (Gold and Parris, 1986; Feiss et al., 1988).

Lambdoid phage 21, which shares the 12 bp cohesive end with $\lambda$ but has a different terminase, fails to grow in him or hip mutants. The block is a failure in terminase action, since phage 21 her mutants, which are proficient for growth in $\mathrm{E}$. coli him or hip mutants, have mutations in a gene encoding one of the subunits of the phage 21 terminase (the analog of Nu1). In vitro, phage 21 packaging requires IHF (Feiss et al., 1985).

Lambda derivatives with any of several mutations in the cos region fail to grow in him or hip mutants because terminase action becomes dependent on IHF. It has been argued that IHF facilitates terminase binding (Bear et al., 1984; Miller and Feiss, 1988). In vitro, the requirement for a host protein can also be met by a $22,000 \mathrm{M}_{\mathrm{r}}$ protein called terminase host factor (THF; Gold and Parris, 1986). Little is known about THF except that under certain conditions it binds preferentially to DNA in the cos region. Whether THF has a role in cos cleavage in vivo awaits further studies.

It is tempting to postulate that IHF (or a substitute host factor) may bend the DNA to facilitate the formation of a higher-order structure that presents the substrate in an appropriate manner for cleavage and packaging. Consistent with this idea are observations that supercoiling improves terminase binding (Feiss et al., 1983) and that $\lambda$ fails to form plaques on a double gyr $B$ himA mutant (Friedman et al., 1984). A mutation (called ohm1 or $m s 1$ ) resulting from a single base pair change in Nu1 suppresses the effects of both phage and host mutations that impose a requirement for IHF in terminase action; i.e., the mutant terminase is IHF independent (Feiss et al., 1988; Granston et al., 1988). Interestingly, studies with a $\lambda$ variant, $\lambda \cos 154$, that grows poorly in him or hip mutants suggest that IHF $\alpha$ may in some circumstances function independently of IHF $\beta$. Bear et al. (1984) found that $\lambda \cos 154$ grows better in a hip/himD mutant than in a himA mutant. Perhaps the IHF $\alpha$ subunit can function as a homodimer or, alternatively, interact with another DNA binding protein.

It is striking that both int and Nut can be altered to produce IHF-independent proteins by single base pair changes. The fact that these simple changes have not occurred in wild-type $\lambda$ suggests that maintenance of IHF's involvement in these functions is under strong positive selection. What is confounding is that one reaction is part of the lysogenic pathway and the other is far along in the lytic pathway.

\section{The cll Protein}

Expression of the $\lambda$ cll protein, which plays a central role in the decision between lysis and lysogeny (Wulff and Rosenberg, 1983), is regulated by IHF (Miller, 1981). Experiments designed to determine the nature of this regulation have yielded contradictory answers. Posttranscriptional control of $c / l$ gene expression was implicated by in vivo studies employing plasmid constructions: in a himAstrain cll was not expressed even though a downstream gene was expressed (Hoyt et al., 1982). In addition, IHF shows specific binding to an IHF site located 3 bp upstream of the $c / l$ Shine-Dalgarno sequence (Craig and Nash, 1984). The role of IHF in cll expression was directly tested using an in vitro transcription-translation system that followed synthesis of the first dipeptide of the cll protein (Peacock et al., 1984); the results from a system directed by DNA (coupled system) were compared with those from a system directed by RNA. IHF stimulated cll synthesis in the coupled system but had no effect when cll RNA was the template. Because expression of a gene upstream of $c / l$ was independent of IHF, it was suggested that IHF was acting on RNA elongation. These disparate results are further complicated by the large number of signals in the region of $c l l$, including promoters in both directions, multiple transcription terminators, and a translation initiation codon. Mahajna et al. (1986) proposed that IHF, by controlling the elongation rate of transcription, influences the formation of secondary structures in RNA. In this way, IHF might allow the cll mRNA to fold into a translatable structure and also influence the formation of a transcription terminator. In assessing these experiments it is important to remember that direct and indirect effects are difficult to distinguish in in vivo experiments, and thus the lack of c/l expression in him or hip mutants might be due to a failure to synthesize the true effector molecule in the absence of IHF.

The cll protein influences the decision for lysogeny in two ways: by initiating expression of $\mathrm{cl}$ repressor and by controlling expression of int (Wulff and Rosenberg, 1983; Echols and Guarneros, 1983). Thus, cll might couple repression and integration partly through IHF control of its expression: dependence on IHF could be a device for monitoring the physiological state of the host (see below).

\section{Other Recombination Events}

\section{Invertible Genetic Element}

Expression of the type 1 fimbriae of E. coli, encoded by $\operatorname{fim} A$, is regulated by a site-specific recombination reaction that inverts a DNA fragment containing a promoter (Abraham et al., 1985). The fimA gene is transcribed only when the invertible sequence is in one orientation. The ability to turn expression on and off is important since fimbriae allow the bacteria to colonize the mucosal surface early in infection, but later in infection render the bacteria more susceptible to phagocytosis by the host. The inversion catalyzed by the products of the fimB and fimE genes requires the action of IHF; inversion does not occur in him or hip mutants (Eisenstein et al., 1987; Dorman and Hig- 
gins, 1987). FimB and FimE are related in sequence to the Int family of proteins (Argos et al., 1986), suggesting that the Fim switch may be a vestige of a cryptic prophage. IHF is also required for fimA expression since him or hip mutants locked in the "on" position show a 7-fold reduction in expression (Dorman and Higgins, 1987).

\section{Transposons}

IHF has been implicated in the recombination transactions of transposable elements IS $1, \gamma \delta$, and IS10. These mobile genetic elements have similar structures, including flanking inverted repeats that are the substrates for the centrally encoded transposase (lida et al., 1983). IHF binds to the inverted repeats of IS1 and bends the DNA at regions that contain IHF sites (Gamas et al., 1987b; Prentki et al., 1987). Transposition-proficient elements can be constructed with as little as 25 bp of the distal end of the right repeat, but when the end is reduced to $20 \mathrm{bp}$, removing part of an IHF site, there is a $99 \%$ loss of activity. Target sites for both IS1 (Gamas et al., 1987b) and $\gamma \delta$ (Wiater and Grindley, 1988) bind IHF. Binding of transposase to a $\gamma \delta$ inserted in a target site inhibits binding of IHF to the target. Interestingly, the major target site for IS1 in pBR322 derives from Th3, a transposon related to $\gamma \delta$ (Gamas et al., 1987b). (It should be noted that IHF sites in cloning vectors such as pBR322 could confuse results of studies testing the activity of putative IHF sites.) Surprisingly, there is no evidence that transposition of either IS1 or $\gamma \delta$ is altered in him or hip mutants.

Direct evidence for a role of IHF in transposon-directed recombination derives from in vitro studies of IS10 transposition (Morisato and Kleckner, 1987). The plasmid substrate contains a Tn10 facsimile: a $1.7 \mathrm{~kb}$ DNA fragment flanked on either side by the outer 70 bp of IS10. Formation of a small circle by recombination at the IS10 ends serves as a measure of transposition. In addition to transposase and supercoiled DNA, this reaction requires IHF, a requirement less efficiently filled by HU. Two lines of evidence support a role for IHF in IS10 action in vivo: first, an IS10-promoted DNA rearrangement is reduced 5- to 9-fold in him or hip mutants (D. Roberts; cited by Morisato and Kleckner, 1987); and second, a deletion of the IS10 IHF site reduces transposition (Way and Kleckner, 1984).

\section{Excisable Element}

A $14.4 \mathrm{~kb}$ genetic element, e14, can be precisely excised from the $\mathrm{E}$. coli chromosome. As with many temperate phages, this excision follows ultraviolet irradiation. Although phage particles are not produced, the excised DNA can reintegrate into the site from which it was excised. This site-specific recombination does not occur in himA mutants. Moreover, two putative IHF binding sites are present in the att site on the excised product (Brody and Hill, 1988).

\section{Replication}

Both himA and hip/himD mutants fail to maintain plasmid pSC101 (Gamas et al., 1986) and a truncated form of plas- mid R6K with only one (the $\gamma$ ) of three overlapping origins of replication (Filutowicz and Appelt, 1988); they also do not support growth of filamentous phage $f 1$ (Greenstein et al., 1988). The replicons involved share a similar structure: an AT-rich enhancer region adjacent to the origin of replication. IHF sites in these AT-rich regions have been shown to bind IHF. There is bending of the DNA in the region of the IHF site of the pSC101 ori, and mutations changing three conserved base pairs of this site result in both a failure of binding and a loss of biological activity (Stenzel et al., 1987).

The results of these experiments are consistent with the notion that IHF enhances replication by helping to wrap the DNA into a higher-order structure that favors initiation at ori. The structurally related $\mathrm{HU}$ protein has been implicated in replication at oriC of E. coli (Dixon and Kornberg, 1984), acting to localize opening of the duplex DNA by the dnaA initiator protein to three tandem repeats of a 13-mer. It has been postulated that HU "coats" oriC to aid in the formation of a higher-order complex that facilitates dnaA action. IHF can substitute for HU (Bramhill and Kornberg, 1988). If coating by a histone-like protein is required in this reaction, it is difficult to see how IHF could do this in a sequence-specific manner, since oriC does not contain an identifiable IHF site. Perhaps in this instance IHF binds DNA nonspecifically.

\section{Partitioning}

Phage P1 lysogenizes as a low-copy-number plasmid that maintains tight control over its segregation, in large measure through a partition system, par (Austin and Abeles, 1983; Friedman et al., 1986). Such partition systems are considered to be prokaryotic analogs of the eukaryotic $\mathrm{mi}$ totic apparatus. The par region contains a site, parS, and genes, parA and parB, encoding two proteins; apparently, binding of ParB to pars mediates the pairing of progeny plasmids prior to their binding to the membrane that ultimately results in the proper distribution of plasmids to daughter cells. IHF facilitates the binding of ParB to parS (Funnell, 1988). Moreover, parS can be subdivided into two regions: a minimal region containing a 13 bp inverted repeat that binds ParB independently of IHF, and an enlarged region that includes adjacent sequences and exhibits IHF-enhanced binding of ParB.

\section{Plasmid Transfer}

Conjugal plasmids such as F and R100 encode a system for transferring DNA that includes functions involved in DNA mobilization and synthesis of morphological structures. A nick at a unique site, oriT, initiates the transfer of single-stranded DNA to a recipient through the plasmidencoded $F$ pilus (Willets and Skurray, 1987). Transfer of $F$ and R100 from him or hip mutants is reduced (Dempsey, 1987; Gamas et al., 1987a). IHF appears to act at two levels in regulating plasmid transfer: First, it is necessary for expression of at least some of the transfer-related functions including the pilus. Second, there are three putative 


\begin{tabular}{|c|c|c|c|}
\hline Genes & Function & $\begin{array}{l}\text { Role of IHF } \\
\text { in Regulation }\end{array}$ & Reference \\
\hline \multicolumn{4}{|l|}{ Bacterial } \\
\hline fimA (E. coli) & fimbriae & positive & Dorman and Higgins, 1987 \\
\hline ilv (E. coli) & $\begin{array}{l}\text { isoleucine-valine } \\
\text { biosynthesis }\end{array}$ & positive & $\begin{array}{l}\text { Friden et al., } 1984 \text {; Friedman et al., 1984; } \\
\text { Pereira et al., } 1988\end{array}$ \\
\hline hag, H2 (S. typhimurium) & flagellin & positive & Szekely et al.. 1983 \\
\hline phes-pheT-himA (E. coli) & $\begin{array}{l}\text { phenylalanyl-tRNA } \\
\text { synthetase and IHFo }\end{array}$ & negative & Mechulam et al., 1987; Miller, 1984 \\
\hline$x y /$ (E. coli) & $\begin{array}{l}\text { utilization of xylose as } \\
\text { carbon source }\end{array}$ & positive & Friedman et al., 1984 \\
\hline \multicolumn{4}{|c|}{ Free Agents (Plasmids, Phages, IS Elements) } \\
\hline tra (plasmids F and R100) & $\begin{array}{l}\text { transfer of plasmid } \\
\text { DNA }\end{array}$ & positive & Dempsey, 1987; Gamas et al., 1987a \\
\hline$c / l(\lambda$ phage $)$ & lysogeny & positive & $\begin{array}{l}\text { Mahajna et al., 1986; Miller, } 1981 \\
\text { Peacock et al., } 1984\end{array}$ \\
\hline pifA and pifB (plasmid F) & exclusion of phage T7 & positive & Kennedy et al., 1988 \\
\hline$A$ and $B$ (Mu phage) & $\begin{array}{l}\text { transposition and } \\
\text { replication }\end{array}$ & positive & Goosen et al., 1984 \\
\hline$C$ (Mu phage) & repressor & positive and/or negative & $\begin{array}{l}\text { Krause and Higgins, 1986; Goosen } \\
\text { et al., } 1984\end{array}$ \\
\hline \multicolumn{4}{|l|}{ Foreign } \\
\hline $\begin{array}{l}P_{A} \text { (Chlamydomonas } \\
\text { promoter) }\end{array}$ & $\begin{array}{l}\text { chloroplast promoter } \\
\text { of unknown origin }\end{array}$ & negative & Thompson and Mosig, 1988 \\
\hline
\end{tabular}

IHF sites adjacent to oriT of R100 (Mclntire and Dempsey, 1987), implicating IHF in the replication required for transfer.

IHF also modulates expression of another set of plasmid genes, the pifCAB operon of $F$. PifC is required for replication of mini-F and regulates expression of the pif operon (Kennedy et al., 1988). Expression of pifA and pifB results in inhibition of phage T7 growth. Mutations in himA or hip/himD reduce the PifA- and PifB-imposed inhibition of $T 7$ growth. A putative IHF site was identified in the -35 region of the pif promoter, suggesting that IHF binding might stimulate transcription.

\section{Gene Expression}

A number of examples illustrate that IHF participates in the regulation of gene expression. Although the mechanisms involved remain obscure, there is evidence that IHF can exert its effect both transcriptionally and posttranscriptionally. In vivo experiments with him or hip mutants present the problem previously discussed in the section on the cll gene of $\lambda$ : the role of IHF in gene expression could be direct or indirect. This discussion will focus on a few additional systerns regulated by IHF. A more complete list can be found in Table 1 .

Mu

Phage Mu fails to grow in him or hip mutants (Miller et al., 1979). Two phage mutants, nuA and pip, selected for growth on himA and hip/himD, respectively, carry alterations in the region of $\mathrm{Mu}$ regulating repressor and early gene expression (Giphart-Gassler et al., 1979; Yoshida et al., 1982). This region includes the converging promoters,
$\mathrm{Pe}$ and $\mathrm{Pc}-2$ (or PcM), directing transcription rightward toward early genes and leftward toward repressor (see Figure 3; reviewed in Goosen and van de Putte, 1987). The pip mutant, containing a change in the -10 region of $\mathrm{Pe}$, expresses higher levels of mRNA. Two overlapping IHF sites oriented in opposite directions have been identified upstream of $\mathrm{Pe}$ and thus downstream of $\mathrm{Pc}-2$. IHF binds to this region, primarily to one sequence (Krause and Higgins, 1986). In vitro and in vivo studies demonstrate that IHF stimulates transcription from $\mathrm{Pe}$, but suggest that IHF both stimulates and inhibits transcription from $\mathrm{PC}-2$ (Krause and Higgins, 1986; Goosen et al., 1984). Using plasmid constructions, van Rijn et al. (1988) found that IHF control of $\mathrm{Pe}$ is maintained when the distance between $\mathrm{Pe}$ and the IHF site is changed, but only if the two sites maintain their same relative positions on the DNA helix. In addition, they found that IHF stimulates PC-2 transcription over a distance as great as $100 \mathrm{bp}$.

It has been proposed that the overlapping IHF sequences might represent a mechanism for regulation of Mu development: binding of IHF to one site would stimulate transcription from one promoter, while binding to the other site would stimulate transcription from the other. Thus repression and expression would be mutually exclusive (Goosen et al., 1984). However, IHF binds selectively to the "bottom"-strand IHF site (Krause and Higgins, 1986), and a change in the "top" IHF site does not influence PC-2 transcription (Goosen et al., 1984). Thus, it is questionable whether the "top" IHF site is functional.

\section{E. coli ilv}

E. coli ilv gene expression is reduced in him or hip mutants (Friden et al., 1984; Friedman et al., 1984), and IHF bind- 


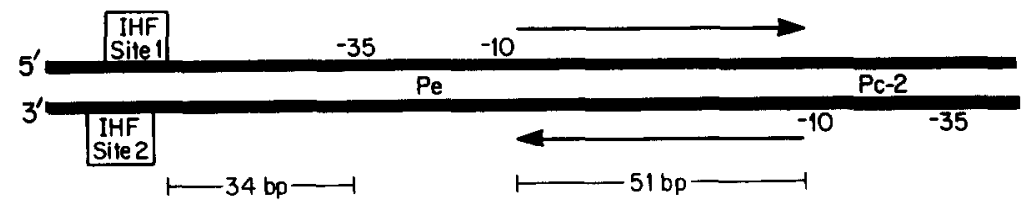

Figure 3. IHF Sites and Promoters in the Early Region of Phage Mu

Arrows show the direction of transcription from the $\mathrm{Pe}$ and $\mathrm{Pc}-2$ promoters. IHF sites are outlined by boxes. Relevant distances are indicated in bp. ing to a region upstream of the IVGEDA operon has been found (Pereira et al., 1988). In vitro transcription studies identified two upstream promoters, Gp1 and Gp2; in vivo, transcription is only observed from Gp2. IHF binds to a 350 bp fragment that includes Gp1 and inhibits transcription from this promoter. Moreover, binding of IHF to the upstream Gp1 promoter region enhances transcription from Gp2. The mechanism for this IHF-directed enhancement is not known, but two explanations seem plausible: First, only transcription from Gp2 successfully transcribes the structural genes, and if transcription from Gp1 occludes transcription from Gp2, there is no expression. The role of IHF in Gp2 transcription would thus be to repress Gp1 transcription. Second, IHF bound near Gp1 may directly stimulate transcription from Gp2.

\section{Chlamydomonal Chloroplast}

Chloroplast promoters resemble those of E. coli, and some are active in E. coli (Whitfield and Bottomley, 1983). Transcription from a Chlamydomonas reinhardtii chloroplast promoter, $P_{A}$, appears to be inhibited by IHF. Employing a plasmid construct with $P_{A}$ and the upstream region from the chloroplast, Thompson and Mosig (1988)

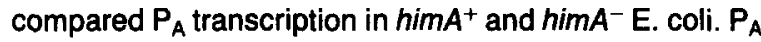

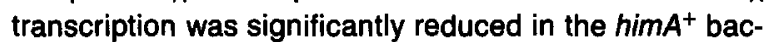
terium. In vitro binding studies showed protection of two putative IHF sites, one overlapping $\mathrm{P}_{\mathrm{A}}$ and the second $\sim 100$ bp upstream of $P_{A}$. IHF inhibits formation of open complexes with $R N A$ polymerase at $P_{A}$. Curiously, in vivo studies failed to prove that either site plays any role in this inhibition. There is no relief from IHF inhibition when the IHF site is specifically deleted from the upstream region, showing that this site is not necessary for inhibition; however, there is relief from IHF inhibition when the upstream region is totally removed, showing that the remaining promoter-associated IHF site is not sufficient for inhibition. Since another E. coli DNA binding protein footprints between the two IHF sites, Thompson and Mosig (1988) have suggested that inhibition results from interactions between the occupied IHF site at the promoter and the upstream region altered perhaps by bound protein. It is also possible that the in vivo role of IHF is secondary, influencing the expression of the actual inhibitory factor. Studies with Chlamydomonas should determine whether the IHF recognition sequence represents a conserved signal.

\section{Structure: A Minor Groover?}

The structure of IHF has not been determined, but a related DNA binding protein, $\mathrm{HBs}$, a homodimer from $\mathrm{Ba}$ cillus stearothermophilus, has been crystallized and ana- lyzed by Tanaka et al. (1984). Their analysis of the X-ray diffraction patterns suggests a structure that has the two subunits intertwined, with a hydrophobic center and long flexible extending arms that could bind within the major or minor groove of double-stranded DNA (see Figure 4). The arms are composed of a two-stranded antiparallel $\beta$-ribbon forming a surface that complements the helix of double-stranded B-DNA. Moreover, the arms contain a number of arginines and lysines, amino acids known to interact with DNA, that can be oriented to make contact with phosphates on one strand of the DNA.

Although IHF is a heterodimer, each subunit shows significant resemblance to the $\mathrm{HBs}$ monomer; e.g., each has the conserved arginines and lysines in a position analogous to the arm region of HBs (Flamm and Weisberg, 1985). Thus it is reasonable to speculate that the IHF het-

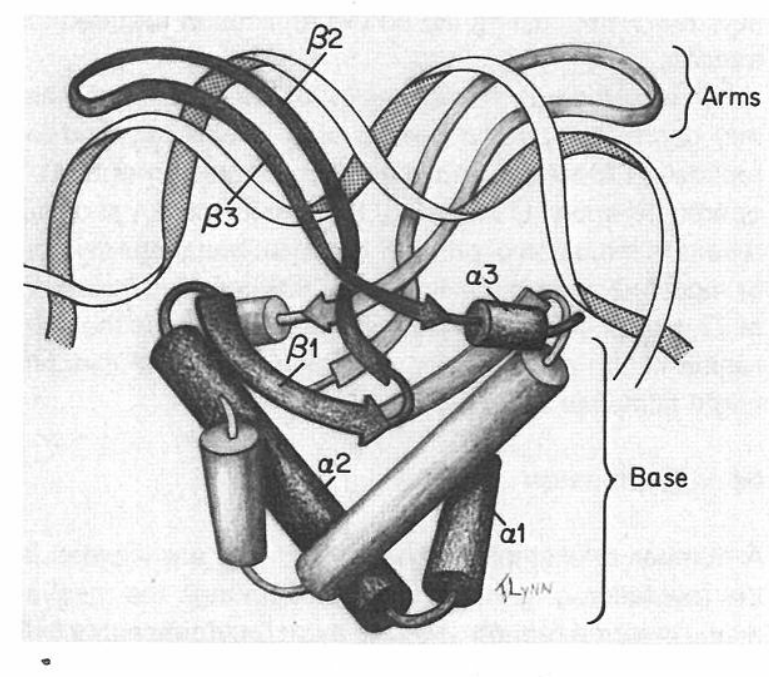

Figure 4. Structure of the Histone-like Protein Hbs, Showing DNA Contacts as Deduced for IHF

The diagram is based on the protein structure derived by Tanaka et al. (1984) and the DNA protection studies of Craig and Nash (1984). The two identical subunits are distinquished by lighter and darker shading. In the case of IHF, a heterodimer would be formed by association of one subunit each of IHF $\alpha$ and IHF $\beta$. Each monomer starting at the amino terminus contributes two $\alpha$-helices (labeled $\alpha 1$ and $\alpha 2$ ) to form the base of the molecule, a three-stranded $\beta$-pleated sheet (the component strands labeled $\beta 1, \beta 2, \beta 3$ ) with strands $\beta 2$ and $\beta 3$ hypothesized as looping out to form the arm that fits in the groove, and a third $\alpha$-helix $(\alpha 3)$ at the carboxyl end that extends from the base. Although the arms are shown docking in the minor groove to reflect the protection data, the precise nature of binding has not been determined, and a more complicated interaction, perhaps including binding to the major groove, has not been ruled out. Similarly, bending of DNA is shown only as a reminder of this activity of IHF; no definitive mechanism is implied. 
erodimer has a structure like that of HBs and that IHF binds to DNA via the predicted long arms. On the basis of results from dimethyl sulfate protection studies, Craig and Nash (1984) proposed that IHF binds in the minor groove. They compared the protection afforded to a number of IHF sites and found the most consistent modifications to be at adenine residues that dimethyl sulfate methylates at the $\mathrm{N}-3$ position in the minor groove. $\mathrm{H}$. Nash and C.-C. Yang (personal communication) interpret results of experiments using IHF to protect the sugar backbone against hydroxyl radical attack as more compelling evidence for minor-groove binding. This technique offers a sensitive assessment of protein-nucleotide contact because there is no dependence on sequence and the small size of the radical yields a precise definition of the protein-nucleotide interaction (Tullius and Dombroski, 1986).

These studies do not rule out the possibility that IHF binds in the major groove. Indeed, the choice of minorgroove binding seems somewhat peculiar since most sequence-specific DNA binding proteins recognize sequences in the major groove (Pabo and Sauer, 1984), presumably because there is significantly more potential for signal heterogeneity (Seeman et al., 1976). However, bending could expand the minor groove to make it more accessible to IHF. Moreover, as noted by Tanaka et al. (1984), an antiparallel $\beta$-ribbon structure like that forming the arms of HBs can fit into the minor groove of B-DNA (Church et al., 1977). Regardless of which groove the arms dock in, the model of Tanaka et al. (1984) predicts that they will cover only one turn of the helix (Figure 4). If this is true, it is difficult to explain the $30-40$ bp observed to be protected in binding studies if one IHF site binds one dimer. Although binding of multiple IHF molecules could explain the protection results, careful measurement of the stoichiometry of binding at two IHF sites in att $P$ shows that only one IHF heterodimer is bound at each site; thus, interaction of IHF with DNA might entail more than binding of the arms (C.-C. Yang and H. Nash, personal communication). Definitive information on binding awaits analysis of the DNA-IHF cocrystal.

\section{Concluding Remarks}

The information presented here highlights the varied physiological processes in which IHF participates. It is noteworthy that many genetic free agents (e.g., phages, transposons, plasmids) use IHF in their independent DNA transactions (e.g., recombination, replication, partitioning, transfer). In addition, IHF stimulates expression of a number of genes, acting in some cases at sites removed from the promoter. We look to features common to these processes for insights into IHF action. With one known exception the involved genes or elements are near one or more sequences resembling the consensus IHF sequence, and in many cases IHF binding and DNA bending have been observed at these sites. IHF does not play a primary role in these processes, but facilitates the action of other proteins by participating in the formation of a higherorder DNA structure. The formation of such structures is likely to depend on the topological state of the DNA par- tially influenced by bends imposed by IHF. Echols (1986) proposed that such specialized nucleoprotein structures ("snups") provide a means for precise site selection in DNA transactions such as replication, recombination, and transcription. Other possible modes of action should not be overlooked; e.g., IHF could bind and act independently of a higher-order structure to facilitate action of other proteins.

Although IHF appears to play an essential role in processes such as cleavage at $\cos _{21}$ and integration of $\lambda$, it is more dispensable in other processes such as cleavage at $\cos _{\lambda}$ and replication of phage f1. Moreover, in both cases mutations can be obtained that permit action in the absence of IHF. The fact that these mutations can be single base pair changes means that there must be strong selective pressure to maintain some form of IHF participation in the reactions, perhaps to direct the formation of a higher-order structure. Because the reactions can occur in the absence of IHF, these structures must not be essential, or they are formed, as suggested by Echols (1986), for the intasome in the absence of IHF. Studies with the int-h mutant address the question of a functional role for IHF. Int-h protein is most effective in the presence of IHF and is substantially more proficient than $\mathrm{Int}^{+}$at catalyzing recombination at secondary att sites (Miller et al., 1980). Because Int $^{+}$and Int-h are equally effective in the presence of IHF at recombination with the primary attB site, it can be argued that the Int ${ }^{+}-$IHF combination confers maximal precision, directing integration to that site.

IHF may exert control over the same event at many levels, influencing both the reactions per se as well as the expression of genes involved in the processes. First pointed out as a feature of $\lambda$ lysogeny (Miller, 1981), multilevel control by IHF has been suggested for another recombination reaction as well as a replication system (Dorman and Higgins, 1987; Filutowicz and Appelt, 1988). We look to $\lambda$ lysogeny as the best studied example of multilevel control. The two activities leading to stable lysogeny are integration and repressor formation. The occurrence of one event independent of the other could be catastrophic for the phage; the unrepressed integrated prophage would kill the host, and the repressed unintegrated prophage would not be replicated and stable lysogeny would not be possible. Thus it is conceivable that IHF aids in the coordination of repression with integration. In addition, IHF activity might serve as a mechanism that links the decision for lysis versus lysogeny with the physiological state of the host.

The specific binding of IHF may play a number of roles. For example, it might ensure that the components of higher-order structures are properly aligned, or it might synchronize a number of physiological activities. Both roles assume variations in IHF activity, which, according to Thompson et al. (1986), are not likely to be explained by concentration differences. However, even if concentration does not change according to the physiological state of the cell, IHF could be such an effector. One plausible scenario would have effective binding of IHF depend on the topological state of the DNA. In this way, the specific binding of IHF could vary in a concentration-independent 
manner with other physiological-sensing factors determining the topological state of the DNA. Indeed, a synergistic effect of certain gyrB and him or hip mutations on supercoiling and gene expression has been observed (Friedman et al., 1984). Finally, it is intriguing to speculate that IHF, like histone proteins in higher organisms (Robbins and Borun, 1967), may be expressed only during one period of the cell cycle. Thus, IHF could be a mechanism to coordinate activities within the microenvironment of the cell.

The remarkably wide-ranging experimental attack on IHF summarized in this review has not, for the most part, resulted from a unified effort, but rather has taken place because IHF through its broad range of activities has forced itself on the collective unconscious of prokaryotic molecular biologists. Now that IHF has emerged from the shadows, we can expect to see rapid advances toward relating its structure to its many activities in the physiology of E. coli.

\section{Acknowledgments}

The author thanks A. Granston, E. Lynch, M. Chandler, B. Eisenstein, M. Imperiale, H. Nash, F. Neidhardt, and R. Weisberg for invaluable help in the writing of this paper, $H$. Nash for encouragement and critical information, Trina Flower for manuscript preparation, and Teryl Lynn for figures. The author apologizes to his many colleagues who supplied unpublished information that could not be cited in this article.

\section{References}

Abraham, J. M., Freitag, C. S., Clements, J. R., and Eisenstein, B. I. (1985). An invertible element of DNA controls phase variation of type 1 fimbriae of Escherichia coli. Proc. Natl. Acad. Sci. USA 82, 57245727.

Argos, P., Landy, A., Abremski, K., Egan, J. B., Haggard-Ljungquist, E., Hoess, R. H., Kahn, M. L., Kalionis, B., Narayana, S. V. L., Pierson, L. S., III, Sternberg, N., and Leong, J. M. (1986). The integrase family of site-specific recombinases: regional similarities and global diversity. EMBO J. 5. 433-440

Austin, S., and Abeles, A. (1983). Partition of unit-copy miniplasmid to daughter cells. I. P1 and F miniplasmids contain discrete, interchangeable sequences sufficient to promote equipartition. J. Mol. Biol. 169, 353-372.

Bear, S. E., Court, D. L., and Friedman, D. I. (1984). An accessory role for $E$. coli integration host factor (IHF): characterization of a lambda mutant dependent upon IHF for DNA packaging. J. Virol. 52, 966-972.

Bear, S. E., Clemens, J. B., Enquist, L. W., and Zagursky, R. J. (1987). Mutational analysis of the lambda int gene: DNA sequence of dominant mutations. J. Bacteriol. 169, 5880-5883.

Better, M., Lu, C., Williams, R. C., and Echols, H. (1982). Site-specific DNA condensation and pairing mediated by the int protein of bacteriophage $\lambda$. Proc. Natl. Acad. Scl. USA 79, 5837-5841.

Better, M., Wickner, S., Auerbach, J., and Echols, H. (1983). Role of the $X i s$ protein of bacteriophage $\lambda$ in a specific reactive complex at the attR prophage attachment site. Cell 32, 161-168.

Bramhill, D., and Kornberg, A. (1988). Duplex opening by dnaA protein at novel sequences in initiation of replication of the $E$. coli chromosome. Cell $52,743-755$.

Brody, H., and Hill, C. W. (1988). Attachment site of genetic element e14. J. Bacteriol, 170, 2040-2044.

Bushman, W., Thompson, J. F., Vargas, L., and Landy, A. (1985). Control of directionality in lambda site specific recombinatlon. Science 230, 906-911.

Campbell, A. (1962). The episomes. Adv. Genet. 11, 101-145.
Campbell, A. (1983). Bacteriophage $\lambda$. In Mobile Genetic Elements, J. Shapiro, ed. (New York: Academic Press), pp. 65-103.

Church, G. M., Sussman, J. L., and Kim, S.H. (1977). Secondary structural complementarity between DNA and proteins. Proc. Natl. Acad. Sci. USA 74, 1458-1462.

Craig, N. L., and Nash, H. A. (1984). E. coli integration host factor binds to specific sites in DNA. Cell $39,707-716$.

Dempsey, W. B. (1987). Integration host factor and conjugative transfer of the antibiotic resistance plasmid R100. J. Bacteriol. 169, 4391-4392.

Dixon, N. E., and Kornberg, A. (1984). Protein HU in the enzymatic replication of the chromosomal origin of Escherichia coli. Proc. Natl. Acad. Sci. USA 81, 424-428.

Dorman, C. J., and Higgins, C. F. (1987). Fimbrial phase variation in E. coli: dependence on integration host factor and homologies with other site-specific recombinases. J. Bacteriol. 169, 3840-3843.

Drlica, K., and Rouviere-Yaniv, J. (1987). Histonelike proteins of bacteria. Microbiol. Rev. 51, 301-319.

Echols, H. (1986). Multiple DNA-protein interactions governing highprecision DNA transactions. Science 233, 1050-1056.

Echols, H., and Guarneros, G. (1983). Control of integration and excision. In Lambda II, R. W. Hendrix, J. W. Roberts, F. W. Stahl, and R. A Weisberg, eds. (Cold Spring Harbor, New York: Cold Spring Harbor Laboratory), pp. 75-92.

Eisenstein, B. I., Sweet, D. S., Vaughn, V., and Friedman, D. I. (1987). Integration host factor is required for the DNA inversion that controls phase variation in Escherichia coli. Proc. Natl. Acad. Sci. USA 84 6506-6510.

Feiss, M. (1986). Terminase and the recognition, cutting and packaging of $\lambda$ chromosomes. Trends Genet. 2. 100-104

Feiss, M., Kobayashi, 1., and Widner, W. (1983). Separate sites for binding and nicking of bacteriophage $\lambda$ DNA by terminase. Proc. Natl. Acad. Scl. USA 80, 955-959.

Feiss, M., Frackman, S., and Sippy, J. (1985). Essential interaction between lambdoid phage 21 terminase and the $E$. colf integrative host factor. J. Mol. Biol. 183, 239-249.

Feiss, M., Fogarty, S., and Christiansen, S. (1988). Bacteriophage lambda DNA packaging: a mutant terminase that is independent of integration host factor. Mol. Gen. Genet. 212, 142-148.

Filutowicz, M., and Appelt, K. (1988). The integration host factor of Escherichia coli binds to multiple sites at plasmid R6K $\gamma$ origin and is essential for replication. Nucl. Acids Res. 16, 3829-3843.

Flamm, E. L., and Weisberg, R. A. (1985). Primary structure of the hip gene of $E$. coli and of its product, the $\beta$ subunit of integration host factor. J. Mol. Biol. 183, 117-128.

Friden, P., Voelkel, K., Sternglanz, R., and Freundlich, M. (1984). Reduced expression of the isoleucine and valine enzymes in integration host factor mutants of Escherichia coli. J. Mol. Biol. 172, 573-579.

Friedman, D. I., Olson, E. J., Carver, D., and Gellert, M. (1984). Synergistic effect of himA and gyrB mutations: evidence that Him functions control expression of $i / v$ and $x y /$ genes. J. Bacteriol. 157, 484-489.

Friedman, S., Martin, K., and Austin, S. (1986). The partition system of the P1 plasmid. In Banbury Report 24, Antibiotic Resistance Genes: Ecology, Transfer, and Expression, S. B. Levy and R. P. Novick, eds. (Cold Spring Harbor, New York: Cold Spring Harbor Laboratory), pp. 285-295.

Funnell, B. E. (1988). Participation of Escherichia coli integration host factor in the P1 plasmid partition system. Proc. Natl. Acad. Sci. USA $85,6657-6661$.

Gamas, P., Burger, A. C., Churchward, G., Caro, L., Galas, D., and Chandler, M. (1986). Replication of pSC101: effects of mutations in the E. coli DNA binding protein IHF. Mol. Gen. Genet. 204, 85-89.

Gamas, P., Caro, L., Galas, D., and Chandier, M. (1987a). Expression of $F$ transfer functions depends on the Escherichia coli integration host factor. Mol. Gen. Genet. 207, 302-305.

Gamas, P., Chandler, M., Prentki, P., and Galas, D. (1987b). Escherichia coli integration host factor binds specifically to the ends of the insertion 
sequence IS1 and to its major insertion hotspot in pBR322. J. Mol. Biol. 195, 261-272.

Gardner, J. F., and Nash, H. A. (1986). Role of Escherichia coli IHF protein in lambda site-specific recombination. A mutational analysis of binding sites. J. Mol. Biol. 191, 181-189.

Giphart-Gassler, M., Goosen, T., VanMeeteren, A., Wijffelman, C., and van de Putte, P. (1979). Properties of the recombinant plasmid pGp1 containing part of the early region of bacteriophage Mu. Cold Spring Harbor Symp. Quant. Biol. 43, 1179-1185.

Gold, M., and Parris, W. (1986). A bacterial protein requirement for the bacteriophage $\lambda$ terminase reaction. Nucl. Acids Res. 14, 9797-9809. Goosen, N., and van de Putte, P. (1987). Regulation of transcription. In Phage Mu, N. Symonds, A. Toussaint, and P. van de Putte, eds. (Cold Spring Harbor, New York: Cold Spring Harbor Laboratory), pp. 41-52.

Goosen, N., Van Heuvel, M., Moolenaar, G. F., and van de Putte, P. (1984). Regulation of Mu transposition. II. The Escherichia coli Hir,1D protein positively controls two repressor promoters and the early promoter of bacteriophage Mu. Gene 32, 419-426.

Granston, A. E., Alessi, D. M., Eades, L. J., and Friedman, D. I. (1988). A point mutation in the Nu1 gene of bacteriophage $\lambda$ facilitates phage growth in Escherichia coli with himA and gyrB mutations. Mol. Gen. Genet. 212, 149-156.

Greenstein, D., Zinder, N. D., and Horiuchi, K. (1988). Integration host factor interacts with the DNA replication enhancer of the filamentous phage f1. Proc. Natl. Acad. Sci. USA 85, 6262-6266.

Hoyt, M. A., Knight, D. M., Das, A., Miller, H. I., and Echols, H. (1982). Control of phage $\lambda$ development by stability and synthesis of cll protein: role of the viral $c / l /$ and host $h H A$, himA and himD genes. Cell 31 , 565-573.

lida, S., Meyer, J., and Arber, W. (1983), Prokaryotic IS elements. In Mobile Genetic Elements, J. Shapiro, ed. (New York: Academic Press), pp. 159-221.

Kennedy, M., Chandler, M., and Lane, D. (1988). Mapping and regulation of the pifC promoter of the F plasmid. Biochim. Biophys. Acta 950, 75-80.

Krause, H. M., and Higgins, N. P. (1986). Positive and negative regulation of the Mu operator by Mu repressor and Escherichia coli integration host factor. J. Biol. Chem. 261, 3744-3752.

Lange-Gustafson, B. J., and Nash, H. A. (1984). Purification and properties of Int-h, a variant protein involved in site-specific recombination of bacteriophage $\lambda$. J. Biol. Chem. 259, 12724-12732.

Leong, J. M., Nunes-Duby, S., Lesser, C. F., Youderian, P., Susskind, M. M., and Landy, A. (1985). The $\varphi 80$ and P22 attachment sites: primary structure and interaction with Escherichia coll integration host factor. J. Biol. Chem. 260, 4468-4477.

Mahajna, J., Oppenheim, A. B., Rattray, A., and Gottesman, M. (1986). Translation initiation of bacteriophage lambda gene cll requires integration host factor. J. Bacteriol. 165, 167-174.

McIntire, S. A., and Dempsey, W. B. (1987). oriT sequence of the antibiotic resistance plasmid R100. J. Bacteriol. 169, 3829-3832.

Mechulam, Y., Fayat, G., and Blanquet, S. (1985). Sequence of the Escherichia coli pheST operon and identification of the himA gene. J. Bacteriol. 163, 787-791.

Mechulam, Y., Blanquet, S., and Fayat, G. (1987). Dual level control of the Escherichia coli pheST-himA operon expression. tRNA ${ }^{\text {Phe-de- }}$ pendent attenuation and transcriptional operator-repressor control by himA and the SOS network. J. Mol. Biol. 197, 453-470.

Miller, G., and Feiss, M. (1988). The bacteriophage $\lambda$ cohesive end site isolation of spacing/substitution mutations that result in dependence on Escherichia coli integration host factor. Mol. Gen. Genet. 212, 157-165.

Miller, H. I. (1981). Multilevel regulation of bacteriophage $\lambda$ lysogeny by the $\mathrm{E}$. coli himA gene. Cell 25, 269-276.

Miller, H. I. (1984). Primary structure of the himA gene of $E$. coli: homology with DNA binding protein $\mathrm{HU}$ and association with the phenylalanyl tRNA synthetase operon. Cold Spring Harbor Symp. Quant. Biol. 49, 691-698.
Miller, H. I. (1988). Viral and cellular control of site-specific recombination. In The Recombination of Genetic Material, B. Low, ed. (New York: Academic Press), pp. 361-384.

Miller, H. I., and Friedman, D. I. (1977). Isolation of Escherichia coli mutants unable to support lambda integrative recombination. In DNA Insertion Elements, Plasmids and Episomes, A. I. Bukhari, J. A. Shapiro, and S. L. Adhya, eds. (Cold Spring Harbor, New York: Cold Spring Harbor Laboratory), pp. 349-356.

Miller, H. I., Kikuchi, A., Nash, H. A., Weisberg, A. A., and Friedman, D. I. (1979). Site-specific recombination of bacteriophage $\lambda$ : the role of host gene products. Cold Spring Harbor Symp. Quant. Biol. 43, 1121-1126.

Miller, H. I., Mozola, M. A., and Friedman, D. I. (1980). int-h: an int mutation of phage $\lambda$ that enhances site-specific recombination. Cell 20 , 721-729.

Miller, H. I., Kirk, M., and Echols, H. (1981). SOS induction and autoregulation of the himA gene for site-specific recombination in Escherichia coli. Proc. Natl. Acad. Sci. USA 78, 6754-6758.

Morisato, D., and Kleckner, N. (1987). Tn10 transposition and circle formation in vitro. Cell 51, 101-111.

Nash, H. A. (1981). Integration and excision of bacteriophage $\lambda$ : the mechanism of conservative site-specific recombination. Annu. Rev. Genet. 15, 143-167.

Pabo, C., and Sauer, R. (1984). Protein-DNA recognition. Annu. Rev. Biochem. 53, 293-321.

Peacock, S., Weissbach, H., and Nash, H. A. (1984). In vitro regulation of phage $\lambda$ cll gene expression by Escherichia coli integration host factor. Proc. Natl. Acad. Sci. USA 81, 6009-6013.

Pereira, R. F., Ortuno, M. J., and Lawther, R. P. (1988). Binding of integration host factor (IHF) to the ilvGp1 promoter of the ilvGMEDA operon of Escherichia coli K12. Nucl. Acids Res. 16, 5973-5989.

Pollock, T. J., and Nash, H. A. (1983). Knotting of DNA caused by a genetic rearrangement. Evidence for a nucleosome-like structure in site-specific recombination of bacteriophage lambda. J. Mol. Biol. 170 , 1-18.

Prentki, P., Chandler, M., and Galas, D. (1987). Escherichia coli integration host factor bends the DNA at the ends of IS1 and in an insertion hotspot with multiple IHF binding sites. EMBO J. 6, 2479-2487.

Richet, E., Abcarian, P., and Nash, H. A. (1986). The interaction of recombination proteins with supercoiled DNA: defining the role of supercoiling in lambda integrative recombination. Cell 46, 1011-1021.

Richet, E., Abcarian, P., and Nash, H. A. (1988). Synapsis of attachment sites during lambda integrative recombination involves capture of a naked DNA by a protein-DNA complex. Cell 52, 9-17.

Robbins, E., and Borun, T. W. (1967). The cytoplasmic synthesis of histone in HeLa cells and its temporal relationship to DNA replication. Proc. Natl. Acad. Sci. USA 57, 409-416.

Robertson, C. A., and Nash, H. A. (1988). Bending of the bacteriophage $\lambda$ attachment site by Escherichia coli integration host factor. J. Biol. Chem. 263, 3554-3557.

Sadowski, P. (1986). Site-specific recombinases: changing partners and doing the twist. J. Bacteriol. 165, 341-347.

Seeman, N. C., Rosenberg, J. M., and Rich, A. (1976). Sequencespecific recognition of double helical nucleic acids by proteins. Proc. Natl. Acad. Sci. USA 73, 804-808.

Stenzel, T. T., Pateł, P., and Bastia, D. (1987). The integration host factor of Escherichia coli binds to bent DNA at the origin of replication of the plasmid pSC101. Cell 49, 709-717.

Szekely, E., Silverman, M., and Simon, M. (1983). Recombinational regulation of flagellin gene expression. In Genetic Rearrangements, $K$. Chater, C. Cullis, D. Hopwood, A. Johnston, and W. Woolhouse, eds. (Sunderlend, Massachusetts: Sinauer Associates), pp. 117-129.

Tanaka, I., Appelt, K., Dijk, J., White, S. W., and Wilson, K. S. (1984). $3-\AA$ resolution structure of a protein with histone-like properties in prokaryotes. Nature 310, 376-381.

Thompson, R. J., and Mosig, G. (1988). Integration host factor (IHF) represses a Chlamydomonas chloroplast promoter in $E$. coli. Nucl. Acids Res. 16, 3313-3326. 
Thompson, J. F., Waechter-Brulla, D., Gumport, R. I., Gardner, J. F., Moitoso de Vargas, L., and Landy, A. (1986). Mutations in an integration host factor-binding site: effect on lambda site-specific recombination and regulatory implications. J. Bacteriol. 168, 1343-1351.

Thompson, J. F., Moitoso de Vargas, L., Skinner, S. E., and Landy, A. (1987). Protein-protein interactions in a higher-order structure direct lambda site-specific recombination. J. Mol. Biol. 195, 481-493.

Tullius, T. D., and Dombroski, B. A. (1986). Hydroxyl radical "footprinting": high-resolution information about DNA-protein contacts and application to $\lambda$ repressor and Cro protein. Proc. Natl. Acad. Sci. USA 83, 5469-5473.

van Rijn, P. A., Goosen, N., and van de Putte, P. (1988). Integration host factor of Escherichia coli regulates early- and repressor transcription of bacteriophage Mu by two different mechanisms. Nucl. Acids Res. 16, 4595-4605.

Way, J. C., and Kleckner, N. (1984). Essential sites at transposon Tn10 termini. Proc. Natl. Acad. Sci. USA 81, 3452-3456.

Weisberg, R. A., and Landy, A. (1983). Site-specific recombination in phage $\lambda$. In Lambda II, R. W. Hendrix, J. W. Roberts, F. W. Stahl, and R. A. Weisberg, eds. (Cold Spring Harbor, New York: Cold Spring Harbor Laboratory), pp. 211-250.

Whitfield, P. T., and Bottomley, W. (1983). Organization and structure of chloroplast genes. Annu. Rev. Plant Physiol. 34, 279-310.

Wiater, L. A., and Grindley, N. D. F. (1988). $\gamma \delta$ transposase and integration host factor bind cooperatively at both ends of $\gamma \delta$. EMBO J. 7 1907-1911.

Willetts, N., and Skurray, R. (1987). Structure and function of the F factor and mechanism of conjugation. In Escherichia coli and Salmonella typhimurium: Cellular and Molecular Biology, F. C. Neidhardt, J. L. Ingraham, K. B. Low, B. Magasanik, M. Schaechter, and H. E. Umbarger, eds. (Washington, D.C.: American Society for Microbiology), pp. 1110-1133.

Wulff, D. L., and Rosenberg, M. (1983). Establishment of repressor synthesis. In Lambda II, R. W. Hendrix, J. W. Roberts, F. W. Stahl, and R. A. Weisberg, eds. (Cold Spring Harbor, New York: Cold Spring Harbor Laboratory), pp. 53-73.

Xin. W., and Feiss, M. (1988). The interaction of Escherichia coli integration host factor with the cohesive end sites of phages $\lambda$ and 21 . Nucl. Acids Res. 16, 2015-2030.

Yoshida, R. K., Miller, J. L., Miller, H. I., Friedman, D. I., and Howe, $M$. M. (1982). Isolation and mapping of Mu nu mutants which grow in him mutants of $E$. coli. Virology $120,269-272$. 